\title{
Nanocomposites Based on Natural Biodegradable Materials: Effect of Post-Preparative $\gamma$-Irradiation on the Swelling Properties
}

\author{
Anjali Bajpai*, Neha Tripathi, Shikha Saxena \\ Department of Chemistry, Government Model Science College, Jabalpur, India \\ Email: ${ }^{* a b s \_112 @ r e d i f f m a i l . c o m ~}$
}

Received September 30, 2013; revised October 30, 2013; accepted November 7, 2013

Copyright (C) 2014 Anjali Bajpai et al. This is an open access article distributed under the Creative Commons Attribution License, which permits unrestricted use, distribution, and reproduction in any medium, provided the original work is properly cited. In accordance of the Creative Commons Attribution License all Copyrights (c) 2014 are reserved for SCIRP and the owner of the intellectual property Anjali Bajpai et al. All Copyright (C) 2014 are guarded by law and by SCIRP as a guardian.

\begin{abstract}
Nanocomposites were prepared by in situ intercalative polymerization of acrylamide/acrylic acid in presence of fuller's earth. Agro- and food industry wastes, sugarcane bagasse and chitin, respectively were used as reinforcing/ adsorbent materials. Effect of $\boldsymbol{\gamma}$-radiation on adsorption characteristics of nanocomposites was evaluated by the comparison of swelling and erosion measurements of the exposed and unexposed samples. Low doses of $\gamma$-radiation improved the characteristics as adsorbents. Better results were obtained for the nanocomposites with polyacrylic acid matrix.
\end{abstract}

\section{KEYWORDS}

Nanocomposites; Sugarcane Bagasse; Chitin; Polyacrylamide; Polyacrylic Acid

\section{Introduction}

Renewable resource based biodegradable eco-friendly natural polymers are excellent candidates for various applications owing to increased worldwide concern about sustainability issues $[1,2]$. However, their application as the components of nanocomposites is limited because of dominant hydrophilic character, fast degradation rate and, in some cases, unsatisfactory mechanical properties, particularly under wet environment. This can be significantly improved by blending with synthetic polymers. An emerging area of nanotechnology is being explored for application into the environmental remediation strategies. Lee and Tiwari critically evaluated the role of organomodified or inorgano-organo-clay or the clay based nano-materials/composites in this context [3]. Layered nanohybrids are heterostructured materials composed of twodimensional inorganic host and intercalating inorganicorganic-, bio-, or polymer guests have been extensively explored to create new multifunctional hybrid systems [4]. The emphasis for future work is on advanced clay-

"Corresponding author. based nanomaterials for use in new approaches to sustainable energy, green environment, and human health [5].

Ionizing irradiation is a promising technique for improvement in the properties of existing and advanced synthetic/hybrid materials. Effect of $\gamma$ irradiation on poly (vinyl alcohol) and bacterial cellulose composites used as packaging materials was studied by swelling measurements [6]. Irradiation of cellulose acetate caused a reduction in the values of molar mass, hydrodynamic volume, real and ideal chain dimensions and its characteristic ratio [7]. Pesticide adsorption capacity of cellulose fibre was improved by high-energy irradiation-initiated grafting of glycidyl methacrylate [8].

Adsorption of radioactive species onto economy and easy to dispose materials has attracted attention of several scientists. Hacıoğlu and co-workers proposed ethylene propylene diene terpolymer (EPDM) to be relatively radiation resistant and a candidate polymer for usage in radioactive waste management [9]. Pyrolysis residues, bentonite and fly ash exhibited appreciable adsorption of radio antimony $\left({ }^{122} \mathrm{Sb}\right.$ and $\left.{ }^{124} \mathrm{Sb}\right)$ [10]. Yildiz and co-workers 
suggested clay and zeolites to be good sorbents in radioactive waste management [11]. Balarama Krishna et al. reported efficiency of immobilized moss as a biosorbent for removal of ${ }^{137} \mathrm{Cs}$ and ${ }^{90} \mathrm{Sr}$ from actual low-level radioactive waste solutions, which was efficient even after three cycles of reuse [12]. Selvakumar et al. studied silver nanoparticles containing carbonized yeast for adsorption of few long-lived active radionuclides [13]. Recently an attapulgite/iron oxide nanocomposite was investigated as a suitable sorbent for nuclear waste management [14]. Curti and co-workers found that mobility of ${ }^{79} \mathrm{SeIV}$ released from radioactive waste could be greatly decreased through uptake on the pyrite surface followed by transformation into a sparingly soluble reduced form [15]. The chitin-based sorbents of animal and fungal origin adsorb $U$ and transuranium elements. Some of them are manufactured commercially in a form suitable for high flow-rates [16].

In the present study vinyl monomers, viz., acrylamide and acrylic acid were intercalatively polymerized in presence of fuller's earth (FE) to prepare nanocomposites with polyacrylamide (PAAm) and polyacrylic acid (PAA) matrices respectively under microwave irradiation. Biodegradable agricultural and marine wastes, namely sugar cane bagasse (SCB) and chitin (CH), besides functioning as adsorbents, acted also as reinforcing fillers. FE is composed of the layered silicates, montmorillonite being the major component. All of the four components of respective nanocomposites thus prepared, i.e., SCB, CH, $\mathrm{FE}$ and PAAm or PAA are well known to possess good adsorption characteristics for organic chemicals and metal ions. $\gamma$-radiation could have been used as the energy source in this preparation but it generally requires high doses. Our interest was to study the effect of low doses of $\gamma$-radiation on improving the adsorption behaviour. It was intended that if radiation does not exert a significant deteriorating influence, these materials could be used for radioactive waste management as well.

\section{Experimental}

Nanocomposites were prepared from SCB, CH and FE by in situ intercalative polymerization of the vinylic monomers, namely acrylamide (AAm) or acrylic acid (AA). The emulsion of finely ground SCB in $\mathrm{NaOH}$ and emulsion of $\mathrm{CH}$ in acetic acid were thoroughly mixed under magnetic stirring with finely powdered FE; AA or AAm; potassium per sulphate (KPS) — a free radical initiator; and N, N'-methylene bisacrylamide (MBA) a cross linker. This mixture was irradiated in a domestic microwave oven. The resulting solid mass was extracted with water to eliminate loosely bound material, and then dried in an air oven. The nanocomposite samples with polyacrylamide matrix (NCPAAm) and polyacrylic acid matrix (NCPAA) were exposed to low doses of $\gamma$-radiation from
${ }^{60}$ Co radiation source. Percent swelling and percent erosion of the irradiated samples were measured using conventional gravimetric procedure.

$$
\begin{gathered}
\% \text { Swelling }=\frac{m_{s}-m_{o}}{m_{o}} \times 100 \\
\% \text { Erosion }=\frac{m_{o}-m_{d}}{m_{o}} \times 100
\end{gathered}
$$

Where $m_{o}$ and $m_{s}$ are the masses of the original and water swollen samples respectively; and $m_{d}$ the mass of sample dried after immersing it in deionized water for 24 h.

\section{Results and Discussion}

Nanocomposites NCPAAm and NCPAA were prepared from low cost inorganic and renewable organic materials, by in situ intercalative polymerization of the monomers AAm or AA respectively by microwave irradiation, with a view to develop a cost effective method. SCB comprises of cellulose, hemicelluloses and lignin. Lignin is soluble in aqueous solution of $\mathrm{NaOH}$ but it was not separated from the reaction mixture during the preparation to: 1) facilitate the binding of matrix; 2) provide extra functionality for adsorption, and 3) introduce a little hydrophobicity to the matrix for prevention of fast microbial degradation. NCPAAm and NCPAA samples immersed in deionized water were stable against biodegradation even for 3 months, whereas moulds grew within a week on SCB or $\mathrm{CH}$ in wet condition. However, upon inoculation with Aspergillus, growth of mycelia was visible to unaided eyes over the nanocomposite samples also in seven days, which indicated possibility of their biodegradation. It was interesting to observe when a NCPAAm sample (about $1 \mathrm{~g}$ ) was immersed in $200 \mathrm{~mL}$ of concentrated methyl orange (MO) solution $(0.3 \mathrm{~g} / \mathrm{L})$, sample adsorbed the dye gradually and the solution became nearly colourless in 15 days. This sample, with MO adsorbed on it, was left as such for another 15 days; it slowly turned black in colour. It was examined for the growth of microbes but no fungal or microbial growth could be detected. It was inferred from UV-visible absorption spectral measurement that black color was due to the degradation of dye.

\subsection{Characterization of NCPAAm and NCPAA}

The FTIR spectrum of NCPAA is presented in Figure 1 along with the spectra of its constituents. FTIR spectral analysis is a very powerful tool for the study of interactions of functional groups even for a multicomponent system. The FTIR spectrum of the nanocomposite NCPAAm is depicted in Figure 2 (along with the spectrum of an irradiated sample). 


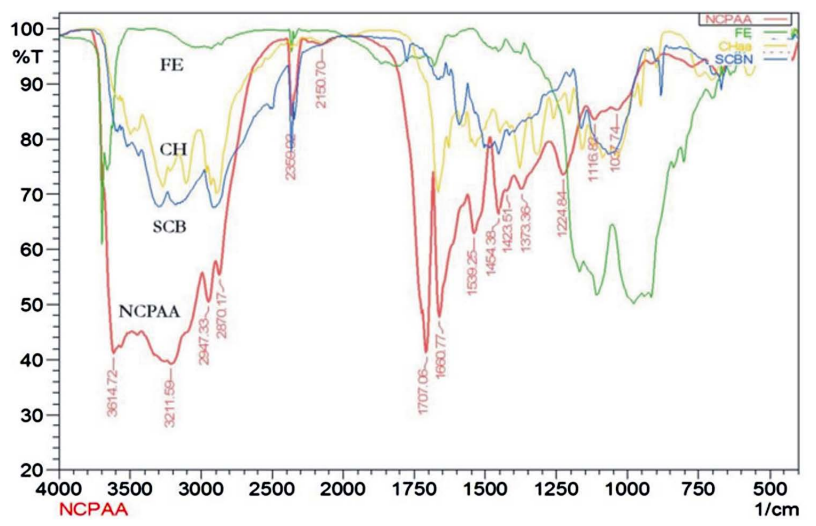

Figure 1. FTIR spectra of NCPAA and its constituents.

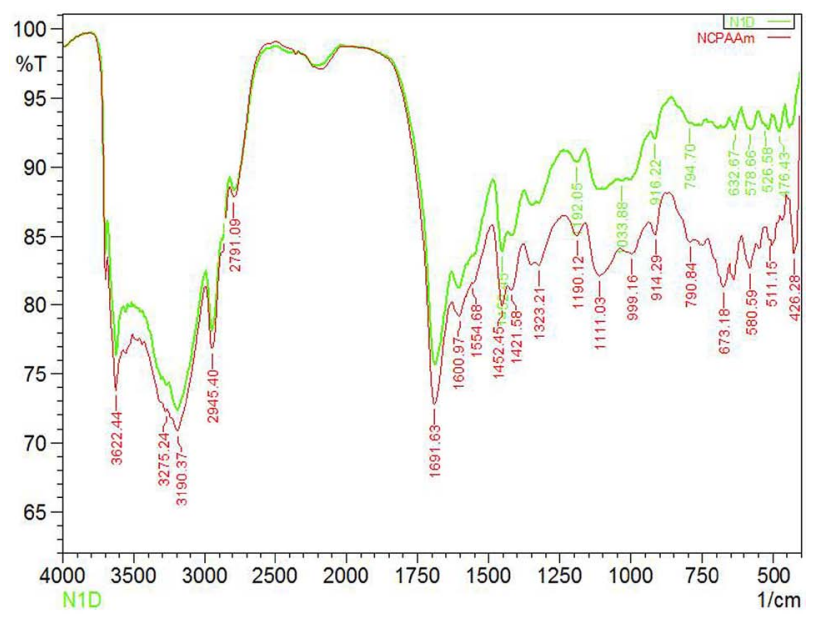

Figure 2. FTIR spectra of NCPAAm (red line: Unexposed) and N1D (green line: sample exposed to $\gamma$-radiation).

The absorption band due to FE (at 3696 and $3665 \mathrm{~cm}^{-1}$ ) was clearly visible above $3610 \mathrm{~cm}^{-1}$ in both the nanocomposites. Decrease in intensity and slight broadening suggested the disruption of layered structure by intercalative polymerization of monomers between the clay interlayers. For NCPAA a very broad and intense band in 2800 - $3700 \mathrm{~cm}^{-1}$ range was observed which included absorptions from $v \mathrm{OH}$ of cellulose, lignin and chitin; and also PAA. Similarly in NCPAAm a broad band centered at $3190 \mathrm{~cm}^{-1}$ appeared due to overlapping absorptions from $v \mathrm{OH}$ and $v \mathrm{NH}$ of SCB, CH and PAAm. The typical $v_{\mathrm{as}} \mathrm{CH}_{2}$ and $v_{\mathrm{s}} \mathrm{CH}_{2}$ appeared around $2900 \mathrm{~cm}^{-1}$. A very strong and broad band in $1650-1800 \mathrm{~cm}^{-1}$ range, was ascribed to the amide I and II vibrations of $\mathrm{CH}$ and PAAm in NCPAAm and COOH groups of NCPAA respectively. This band also included absorptions from $\delta \mathrm{OH}$ and $\delta \mathrm{NH}_{2}$ of SCB and $\mathrm{CH}$. The intensity of this band led to infer that it might have included absorption from carbonyl groups also because it is possible that microwave heating induced oxidation of hydroxyl groups of SCB and CH. Similar phenomenon was reported by Briones and co-workers that under the influence of micro- wave heating lignocellulosic residues showed strong absorption bands at $1730 \mathrm{~cm}^{-1}$ ( $\mathrm{C}=\mathrm{O}$ stretching). They attributed a higher content of carbonyl groups in the MW treated products to the fact that microwave activation induced more intensive oxidation of hydroxyl groups into carbonyl groups [2]. The spectral region below $1500 \mathrm{~cm}^{-1}$ showed a very complex series of overlapping absorption bands, originating from the various components of the nanocomposites.

SEM images of the fractured surfaces of nanocomposites with various magnifications are shown in Figure 3. Inhomogeneous morphology with irregular pores of 5 to $1000 \mu \mathrm{m}$ diameter are visible at low magnification. A few fibres of SCB of 5 to $500 \mu \mathrm{m}$ length are visible on the surface of nanocomposite at lower magnification. The $\mathrm{CH}$ flakes and SCB microfibrils coated with PAA or PAAm appeared as bright areas and the dark areas represented fuller's earth. At magnification of 4000 no pores were visible, which suggested that $\mathrm{CH}$ and SCB were completely embedded in the polymeric matrix intercalated within FE.

The XRD patterns of NCPAAm, NCPAA and FE in $2 \Theta$ range of $0^{\circ}$ to $80^{\circ}$ are depicted in Figure 4. The XRD pattern of NCPAAm exhibited very weak signals corresponding to those of FE. However, the prominent peaks of FE below $10^{\circ}$ reduced to a shoulder and that at $26.55^{\circ}$ also appeared with a decreased intensity. The dspacing of the signal at $27^{\circ}$ calculated by Bragg's equation increased from $3.3543 \AA$ to $3.3814 \AA$ in NCPAAm. The decreased intensity and increased width indicated the presence of disordered or exfoliated regions. The XRD pattern of NCPAA showed the featureless diffraction pattern except for a weak signal at $27^{\circ}$. This type of pattern is generally associated with the exfoliated structure, as a consequence of disrupted coherent layer stacking. Hence it was inferred that intercalation of the polymer chains increased the interlayer spacing of clay (FE) and introduced the amorphous nature. These results proved
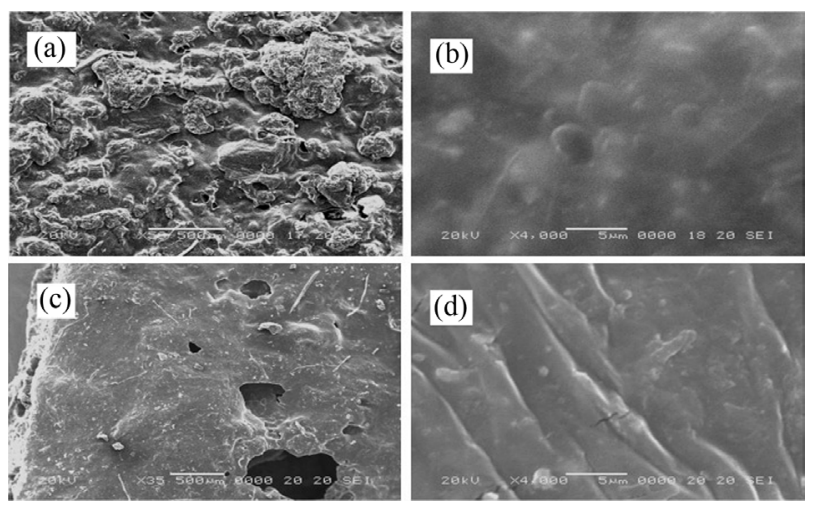

Figure 3. SEM of Fractured surfaces of nanocomposites: NCPAAm-magnifications (a) $\times 50$ (b) $\times 4000$ and NCPAA magnifications (c) $\times 35$ (d) $\times 4000$. 


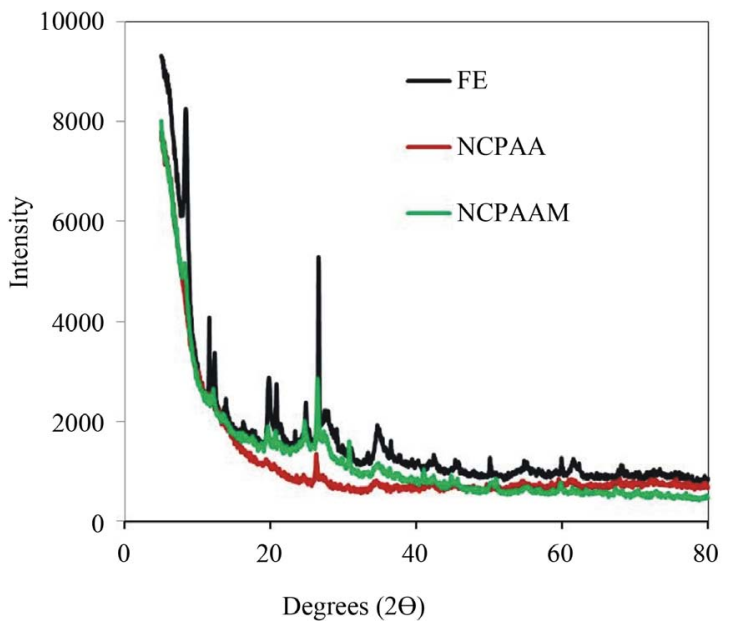

Figure 4. XRD patterns of fuller's earth, NCPAA and NCPAAm.

nanocomposite nature of the samples, since the polymer nanocomposites are materials in which nanoscopic inorganic particles, typically $10-100 \AA$ in at least one dimension, are dispersed in an organic polymer matrix in order to dramatically improve the performance properties of the polymer.

\subsection{Effect of $\gamma$-Irradiation}

The properties required for a good adsorbent for dissolved substances are: extensive surface area and release of minimum amount of leachates, which could be evaluated by measurement of the percent swelling and percent erosion, respectively. In the present study, the nanocomposites were exposed to low radiation doses $(0.25$ $1 \mathrm{kGy}$ ) and the results are depicted in Table 1 , Figures 5 and 6.

A perusal of these data showed that erosion of NCPAAm increased upon irradiation, whereas there was no significant influence on swelling behaviour. Irradiated NCPAA samples exhibited increase in swelling capacity and decrease in percent erosion in water. It has been reported that for chitosan (partially deacetylated chitin) the main chain scission predominated over crosslinking under $\gamma$-irradiation $[17,18]$. Usually the main chain scission promotes the adsorption capacity. It was reported on the basis of study of degradation by irradiation that reduction in molecular weight led to a significant increase in the amount of fat bound by $1 \mathrm{~g}$ of chitosan [19]. One may expect a linear or regular trend for influence on the properties of a material on exposure to increasing doses of radiation. However, the irregular trend observed in the present study could be explained as follows. Exposure to radiation is expected to induce degradation of polymeric chains and also formation of crosslinks through the intermediacy of free radicals. Cross linking should prevent erosion of the matrix but with consequent decrease in
Table 1. Percent erosion of $\gamma$-ray exposed nanocomposite samples.

\begin{tabular}{cccccc}
\hline S. No. & $\begin{array}{c}\text { Exposure } \\
\text { dose kGy }\end{array}$ & $\begin{array}{c}\text { Sample } \\
\text { code }^{*}\end{array}$ & $\begin{array}{c}\text { Erosion } \\
\%\end{array}$ & $\begin{array}{c}\text { Sample } \\
\text { code }^{*}\end{array}$ & $\begin{array}{c}\text { Erosion } \\
\%\end{array}$ \\
\hline 1 & 0.00 & N1 & 1.42 & N2 & 10.68 \\
2 & 0.25 & N1A & 2.36 & N2A & 03.51 \\
3 & 0.50 & N1B & 2.80 & N2B & 06.71 \\
4 & 0.75 & N1C & 4.63 & N2C & 04.33 \\
5 & 1.00 & N1D & 5.50 & N2D & 05.65 \\
\hline
\end{tabular}

${ }^{*} \mathrm{~N} 1$ and N2 denote NCPAAm and NCPAA samples respectively.

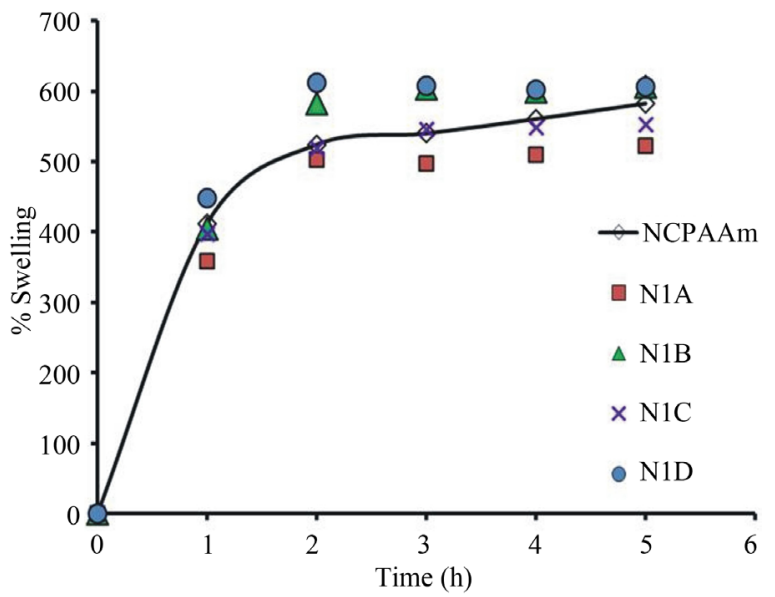

Figure 5. Swelling kinetics of NCPAAm and $\gamma$-ray exposed samples.

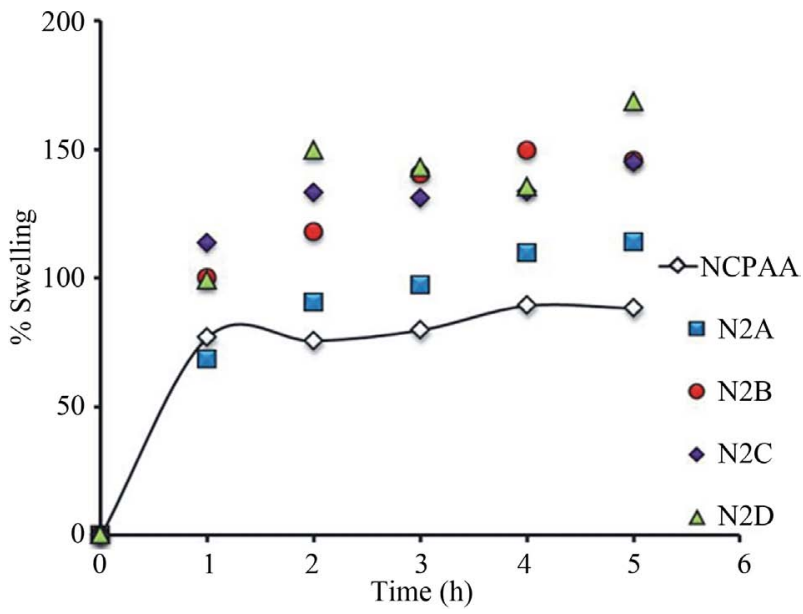

Figure 6. Swelling kinetics of NCPAA and $\gamma$-ray exposed samples.

swelling. The partial degradation of one or more of the matrix components would result in the formation micropores and consequent increase the surface area, whereby swelling would be enhanced. Nevertheless, with a multicomponent system comprising of biopolymers SCB and $\mathrm{CH}$ and interpenetrating network of PAAm or PAA, a partially degraded fragment of one component instead of being separated and lost away, could become attached 
to other component by second order radical reactions. Further, due to presence of lignin (a component of SCB) physical crosslinks by assemblage of hydrophobic moieties also existed and the samples did not behave like typical hydrogels.

A comparison of FTIR spectra of irradiated samples with those of the original samples (Figures 2 and 7) indicated that there was almost negligible effect of $\gamma$-radiation in low doses on the average composition of nanocomposites especially for NCPAAm (Figure 2), i.e., the interaction of functional groups in polyacrylamide matrix was not promoted by $\gamma$-radiation. A slight change was observed for NCPAA (Figure 7). A broad absorption band at $1743 \mathrm{~cm}^{-1}$ in the original sample become narrower in N2D. This broad band incorporated absorption from various functional groups of the constituents, viz. $\mathrm{OH}$ (SCB), - $\mathrm{COOH}$ (PAA), $\mathrm{NH}_{2}$ and $\mathrm{CONH}_{2}(\mathrm{CH})$. Narrowing of this band suggested that there was extensive interaction between these functional groups to form ester (-COO) and amide (-CONH-) linkages. These linkages crosslinked different constituents, consequently the matrix became more compact and the water molecules adsorbed on various constituents were expelled out. This led to decreased erosion. The crosslinks enhanced the surface area of embedded voids, which resulted in increased swelling capacity.

These experiments were carried out with samples cut from the hard, disc shaped product obtained on MW irradiation of reaction mixture in a beaker. When this product was cut into smaller pieces, the sides fractured and very small fragments detached from the main body which amounted to the erosion. Hence, more experiments were carried out with the entire disc shaped block and results are presented in Figure 8. The radiation dose was increased and swelling and erosion were measured for the longer duration. It was appreciated that the erosion was negligible and swelling of irradiated samples enhanced when compared to the virgin sample.

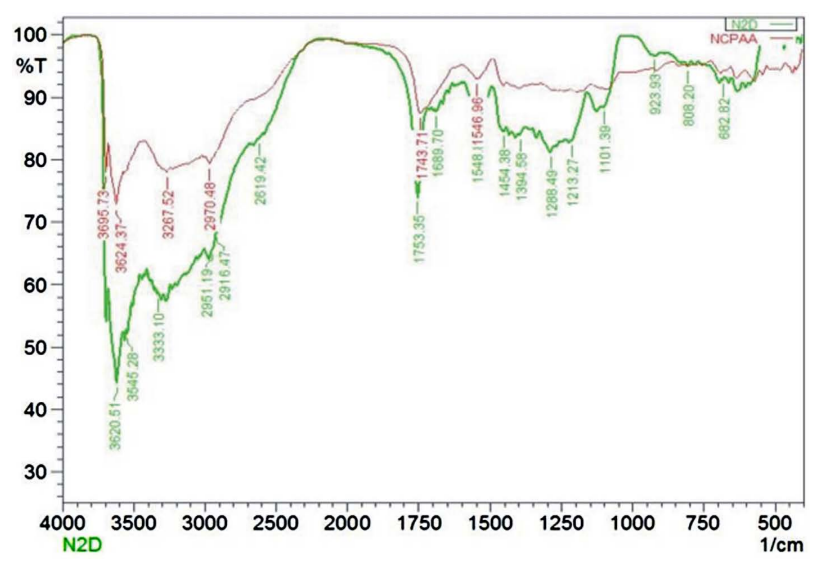

Figure 7. FTIR spectra of NCPAA (red line: Unexposed) and N2D (green line: sample exposed to $\gamma$-radiation).

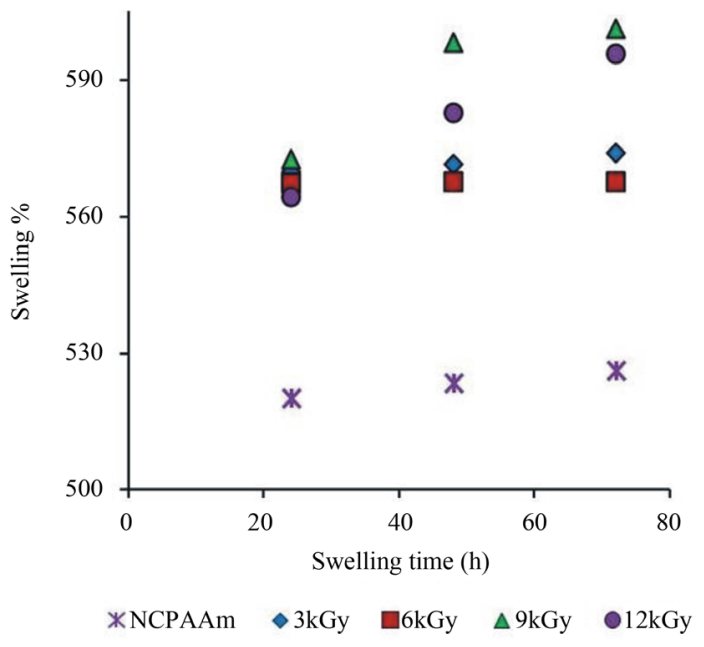

Figure 8. Effect of radiation dose on swelling of NCPAAm.

\section{Conclusion}

Agricultural waste sugarcane bagasse (SCB) and marine industry waste chitin $(\mathrm{CH})$ were incorporated into nanocomposites comprising of organic-inorganic matrix, i.e., synthetic vinylic polymers (PAA and PAAm) and fuller's earth with a view to prepare eco-friendly adsorbents for treatment of polluted water. Effect of $\gamma$-irradiation for improvement in the quality of these materials, viz. enhanced adsorption and minimization of leachate formation was studied. The preliminary investigation showed quite encouraging results. The materials were found to be sufficiently resistant to radiation and their properties as adsorbents were improved.

\section{Acknowledgements}

The authors are thankful to Dr. S. S. Shukla, Radiology department, Jawaharlal Nehru Agriculture University, Jabalpur for $\gamma$-radiation of samples. A part of this work was performed at UGC-DAE Consortium for Scientific Research, Indore. Authors confer gratefulness to the Dr. Ajay Gupta, Center-Director, Indore Center, UGC-DAE Consortium for Scientific Research, Indore. Special thanks are due to Dr. Mukul Gupta, Dr. V. Ganesan, Dr. A. M. Awasthi, Dr. N. P. Lalla and Shri S. Poddar, Mr. A. Gome, Ms. L. Behera, Dr. V. K. Ahire, Mr. S. Bharadwaj, Mr. S Shanmukharao Samatham, Mr. D. Tiwari, Mr S.M. Amir from UGC-DAE Consortium for Scientific Research, Indore.

\section{REFERENCES}

[1] M. He, M. Xu and L. Zhang, "Controllable Stearic Acid Crystal Induced High Hydrophobicity on Cellulose Film Surface," Applied Clay Science, Vol. 5, No. 3, 2013, pp. 585-591. http://dx.doi.org/10.1021/am3026536

[2] R. Briones, L. Serrano, A. Sequeiros and J. Labidi, “In- 
fluence of Microwave Heating on Chemical Properties of Liquefied Lignocellulosic Residues," Radiation Physics and Chemistry, Vol. 52, No. 8, 2013, pp. 2755-2761. http://dx.doi.org/10.1021/ie3026136

[3] S. M. Lee and D. Tiwari, "Organo and Inorgano-OrganoModified Clays in the Remediation of Aqueous Solutions: An overview,” Applied Clay Science, Vol. 59-60, 2012, pp. 84-102. http://dx.doi.org/10.1016/j.clay.2012.02.006

[4] D.-H. Park, S.-J. Hwang, J.-M. Oh, J.-H. Yang and J.-H. Choy, "Polymer-Inorganic Supramolecular Nanohybrids for Red, White, Green, and Blue Applications,” Progress in Polymer Science, Vol. 38, No. 10-11, 2013, pp. 14421486.

http://dx.doi.org/10.1016/j.progpolymsci.2013.05.007

[5] C. H. Zhou and J. Keeling, "Fundamental and Applied Research on Clay Minerals: From Climate and Environment to Nanotechnology,” Applied Clay Science, Vol. 74, 2013, pp. 3-9.

http://dx.doi.org/10.1016/j.clay.2013.02.013

[6] A. Stoica-Guzun, M. Stroescu, I. Jipa, L. Dobre and T. Zaharescu, "Effect of $\gamma$ Irradiation on Poly(Vinyl Alcohol) and Bacterial Cellulose Composites Used as Packaging Materials," Radiation Physics and Chemistry, Vol. 84, 2013, pp. 200-204.

http://dx.doi.org/10.1016/j.radphyschem.2012.06.017

[7] F. EL-Ashha, L. Sheha, M. Abdalkhalek and A. Khalaf, "The Influence of Gamma Irradiation on the Intrinsic Properties of Cellulose Acetate Polymers," Journal of the Association of Arab Universities for Basic and Applied Sciences Vol. 14, No. 1, 2013, pp. 46-50. http://dx.doi.org/10.1016/j.jaubas.2012.12.001

[8] E. Takács, L. Wojnárovits, K. E. Horváth, T. Fekete and J. Borsa, "Improvement of Pesticide Adsorption Capacity of Cellulose Fibre by High-Energy Irradiation-Initiated Grafting of Glycidyl Methacrylate," Radiation Physics and Chemistry, Vol. 8, No. 9, 2012, pp. 1389-1392.

http://dx.doi.org/10.1016/j.radphyschem.2011.11.016

[9] F. Hacıoğlu, T. Özdemir, S. Çavdar and A. Usanmaz, "Possible use of EPDM in Radioactive Waste Disposal: Long Term Low Dose Rate and Short Term High Dose Rate Irradiation in Aquatic and Atmospheric Environment," Radiation Physics and Chemistry, Vol. 83, 2013, pp. 122-130.

http://dx.doi.org/10.1016/j.radphyschem.2012.10.011

[10] M. W. Abdel Raouf, N. Zakareia and A. Alian, “Adsorption of $\mathrm{Sb}(\mathrm{V})$ from Radioactive Organic Waste Solutions on Different Adsorbents," Journal of Radioanalytical and Nuclear Chemistry, Vol. 214, 1996, pp. 41-50. http://dx.doi.org/10.1007/BF02165057

[11] B. Yildiz, H. N. Erten and M. Kis, "The Sorption Behavior of Cs + Ion on Clay Minerals and Zeolite in Radi- oactive Waste Management: Sorption Kinetics and Thermodynamics," Journal of Radioanalytical and Nuclear Chemistry, Vol. 288, No. 2, 2011, pp. 475-483. http://dx.doi.org/10.1007/s10967-011-0990-5

[12] M. V. Balarama Krishna, J. Arunachalam, M. Murali, S. Kumar and V. K. Manchanda, "Performance of Immobilized Moss in the Removal of ${ }^{137} \mathrm{Cs}$ and ${ }^{90} \mathrm{Sr}$ from Actual Low-Level Radioactive Waste Solutions," Journal of Radioanalytical and Nuclear Chemistry, Vol. 261, No. 3, 2004, pp. 551-557. http://dx.doi.org/10.1023/B:JRNC.0000037095.91380.dd

[13] R. Selvakumar, S. Aravidh, C. P. Kaushik, V. G. Katarani, V. S. Thorat, P. Gireesan, V. Jayavignesh, K. Swaminathan and R. Kanwar, "Screening of Silver Nanoparticles Containing Carbonized Yeast Cells for Adsorption of Few Long-Lived Active Radionuclides,” Journal of Radioanalytical and Nuclear Chemistry, Vol. 288, No. 2, 2011, pp. 629-633. http://dx.doi.org/10.1007/s10967-011-0997-y

[14] L. Chen, X. Jinzhang and J. Hu, "Removal of U(VI) from Aqueous Solutions by using Attapulgite/Iron Oxide Magnetic Nanocomposites," Journal of Radioanalytical and Nuclear Chemistry, Vol. 297, No. 1, 2013, pp. 97-105. http://dx.doi.org/10.1007/s10967-012-2360-3

[15] E. Curti, L. Aimoz and A. Kitamura, "Selenium Uptake onto Natural Pyrite,” Journal of Radioanalytical and Nuclear Chemistry, Vol. 295, No. 3, 2013, pp. 1655-1665. http://dx.doi.org/10.1007/s10967-012-1966-9

[16] R. A. A. Muzzarelli, "Potential of Chitin/Chitosan-Bearing Materials for Uranium Recovery: An Interdisciplinary Review," Carbohydrate Polymers, Vol. 84, No. 1, 2011, pp. 54-63.

http://dx.doi.org/10.1016/j.carbpol.2010.12.025

[17] P. Ulanski and J. Rosiak, "Preliminary Studies on Radiation-Induced Changes in Chitosan,” International Journal of Radiation Applications and Instrumentation. Part C. Radiation Physics and Chemistry, Vol. 39, No. 1, 1992, pp. 53-57. http://dx.doi.org/10.1016/1359-0197(92)90171-B

[18] M. H. Casimiro, M. L. Botelho, J. P. Leal and M. H. Gil, "Study on Chemical, UV and Gamma Radiation-Induced Grafting of 2-hydroxyethyl methacrylate onto Chitosan," Radiation Physics and Chemistry, Vol. 72, No. 6, 2005, pp. 731-735.

http://dx.doi.org/10.1016/j.radphyschem.2004.04.029

[19] R. Czechowska-Biskup, B. Rokita, P. Ulanski and J. M. Rosiak, "Radiation-Induced and Sonochemical Degradation of Chitosan as a Way to Increase its Fat-Binding Capacity," Nuclear Instruments and Methods in Physics Research Section B: Beam Interactions with Materials and Atoms, Vol. 236, No. 1-4, 2005, pp. 383-390. http://dx.doi.org/10.1016/j.nimb.2005.04.002 